\title{
Age-related changes in concentrations of vasopressin in the central nervous system and plasma of the male Wistar rat
}

Citation for published version (APA):

Terwel, D., Markerink, M., \& Jolles, J. (1992). Age-related changes in concentrations of vasopressin in the central nervous system and plasma of the male Wistar rat. Mechanisms of Ageing and Development, 65(2-3), 127-136. https://doi.org/10.1016/0047-6374(92)90029-D

Document status and date:

Published: 01/01/1992

DOI:

10.1016/0047-6374(92)90029-D

Document Version:

Publisher's PDF, also known as Version of record

Please check the document version of this publication:

- A submitted manuscript is the version of the article upon submission and before peer-review. There can be important differences between the submitted version and the official published version of record.

People interested in the research are advised to contact the author for the final version of the publication, or visit the DOI to the publisher's website.

- The final author version and the galley proof are versions of the publication after peer review.

- The final published version features the final layout of the paper including the volume, issue and page numbers.

Link to publication

\footnotetext{
General rights rights.

- You may freely distribute the URL identifying the publication in the public portal. please follow below link for the End User Agreement:

www.umlib.nl/taverne-license

Take down policy

If you believe that this document breaches copyright please contact us at:

repository@maastrichtuniversity.nl

providing details and we will investigate your claim.
}

Copyright and moral rights for the publications made accessible in the public portal are retained by the authors and/or other copyright owners and it is a condition of accessing publications that users recognise and abide by the legal requirements associated with these

- Users may download and print one copy of any publication from the public portal for the purpose of private study or research.

- You may not further distribute the material or use it for any profit-making activity or commercial gain

If the publication is distributed under the terms of Article $25 \mathrm{fa}$ of the Dutch Copyright Act, indicated by the "Taverne" license above, 


\title{
AGE-RELATED CHANGES IN CONCENTRATIONS OF VASOPRESSIN IN THE CENTRAL NERVOUS SYSTEM AND PLASMA OF THE MALE WISTAR RAT
}

\author{
DIRK TERWEL, MARJANNE MARKERINK and JELLEMER JOLLES
}

Department of Neuropsychology and Psychobiology, University of Limburg, P.O. Box 616, 6200 MD Maastricht (The Netherlands)

(Received February 4th, 1992)

\section{SUMMARY}

The results of studies on the influence of age on concentrations of vasopressin (VP) in blood plasma and hypothalamic and extrahypothalamic brain sites have not been unequivocal. Studies on extrahypothalamic concentrations of VP in the aging rat have used two age groups only and have mainly provided semiquantitative data. For these reasons we determined, by radioimmunoassay, the concentrations of vasopressin in thirteen brain structures and in the plasma of 3-, 10-, 20- and 28month-old male Wistar rats. Age-related decreases in VP concentrations were found in the pituitary gland, hypothalamus, thalamus, midbrain, medulla oblongata, amygdala and pineal gland, while an increase was noted in plasma. Decreases in the concentration of VP in the amygdala and pineal gland occurred between 3 and 10 months of age and probably represent developmental changes. In the pituitary, thalamus, midbrain, medulla oblongata and plasma, differences in the concentration of VP were also found between 10-month-old and older animals and are probably related to aging. The finding of increased plasma VP concentrations in aged animals agrees with the notion that neuronal function does not necessarily decline with age and suggests that neurons may even be activated. Age-related changes in VP concentrations were not observed in the other structures examined. It has been reported that the VP innervation of a number of brain structures depends on testosterone. Despite reports to the contrary VP concentrations do not generally decline in these structures with aging.

Key words: Vasopressin; Brain; Aging

Correspondence to: D. Terwel, Department of Neuropsychology and Psychobiology, P.O. Box 616,6200 MD Maastricht, The Netherlands. 


\section{INTRODUCTION}

Studies on age-related changes in concentrations of neuropeptides in the rat central nervous system have mainly focused on the neuroendocrine system [1]. Interest in these changes has arisen from the notion that the most elementary characteristic of the aging process is a loss of integration [2]. Neuropeptides are important integratory principles in extrahypothalamic sites in the brain. However, only a limited number of reports on the influence of age on the concentrations of neuropeptides in extrahypothalamic brain areas have appeared [3-7]. Studies on VP have been most extensive, because this peptide is implicated in a number of central and peripheral processes that display changes associated with aging [8-11], such as cardiovascular regulation [12], thermoregulation [13], regulation of fluid balance [14] and memory [15]. VP is synthesized in the neuroendocrine nuclei of the hypothalamus, suprachiasmatic nuclei, bed nucleus of the stria terminalis, medial amygdala, locus coeruleus (for e.g. see Refs. 16 and 17) and probably the pineal gland [18]. From these sites VP is transported to its sites of action.

Data concerning the effects of aging on the hypothalamo-neurohypophyseal system are inconsistent [10,19]. For instance, increased, unaltered and reduced concentrations of VP have been found in aged rats of the Long-Evans strain [19], the Fischer 344 strain $[20,21]$ and the Sprague-Dawley and Fischer 344 strains [22,23], respectively. Similarly, concentrations of VP in the hypothalamus were reduced in aged rats of the Sprague-Dawley [22] and Long-Evans strains [19,24], and reduced [23] or equal [20,21] in the Fischer 344 strain. Concentrations of VP in the pituitary gland were equal (Sprague-Dawley [22], Fischer 344 [23], Long-Evans [24]) or reduced (Fischer 344 [20], Long-Evans [19]).

Reports about the influence of age on extrahypothalamic VP concentrations are more scarce [24-26]. Dorsa and Bottemiller [24] assessed, by radioimmunoassay, extrahypothalamic concentrations of VP in 3- and 26-month-old Long-Evans rats. These authors found reduced concentrations of VP in the dorsal septum, vascular organ of the lamina terminalis and locus coeruleus. Fliers et al. [25] and Goudsmit et al. [26] used immunocytochemistry to study VP concentrations in 3- and 34- and 5- and 34-month-old Brown-Norway rats. In the former study reduced staining of vasopressinergic fibers was found in a number of extrahypothalamic brain regions, such as the lateral septum, the lateral habenula, the medial amygdala and the central gray, but in the latter study a reduction was found in the central gray only.

In the present study we measured VP concentrations in the hypothalamus, pituitary, plasma and extrahypothalamic brain structures of 3-, 10-, 20- and 28month-old male Wistar rats. We performed this study for several reasons. First, information on extrahypothalamic changes in rats is scarce and inconclusive. Second, previous studies examined two age groups only. This has the drawback that it is very difficult to infer whether differences found between two age groups are a manifestation of brain development or brain aging [27]. Third, up to now most 
information has been obtained in semiquantitative studies, the limitations of which are obvious. Fourth, little is known about the course of extrahypothalamic changes in rats with age, which necessitates investigations with more than three age groups. Moreover, data on changes in the hypothalamo-neurohypophyseal system of Wistar rats are scarce. The Wistar rat is relevant in this respect, since from available data it seems that changes in the fluid balance in this strain [28] resemble those in humans (for e.g. see Refs. 29 and 30).

\section{MATERIALS AND METHODS}

\section{Experimental animals}

In the present study male outbred Wistar rats (Bor:WISW(SPFCpb)) were used. The rats were purchased from Winkelmann (Borchen, F.R.G.) at 2 months of age and were kept under controlled environmental conditions $(12 / 12 \mathrm{~h}$ light/dark cycle, free access to food and water). The 50\% survival age of the strain of rats used is 28 months. Animals were handled once a day in the week preceding the experiment. A total of 28 rats were used, divided over four groups of 3-, 10-, 20- and 28-month-old animals.

\section{Brain dissection and plasma collection}

Rats were decapitated at midday and trunk blood was collected in heparinized tubes for the determination of plasma VP concentrations. The brains were removed from the skull and dissected in a cold room for the determination of VP concentrations in different parts of the brain. The brain was cut at the optic chiasm to make anatomical landmarks visible. The tissue block delimited by the corpus callosum, ventricles and the fimbria hippocampus was taken as the septum. The tissue rostral from the tranversal cut and ventral to the septum, anterior commissure and fissura rhinalis was taken as the preoptic area. The midbrain and hypothalamus-thalamus were separated by a cut rostral to the mamillary bodies. The rest of the dissection was performed according to Gispen et al. [31].

\section{Extraction of $V P$ and radioimmunoassay of $V P$}

VP was extracted from plasma and brain samples and concentrations of VP were determined as reported elsewhere [32]. Briefly, acidic brain tissue homogenates were boiled, centrifuged and lyophilized. The freeze-dried material was washed in $50 \%$ ethanol and spun down. Ethanol fractions were evaporated under vacuum. Residues were taken up in assay buffer. Radioimmunoassay was performed in a volume of 100 $\mu l$ using antiserum WI, characterized by Burbach et al. (1984), in a dilution of 1:512 000. Assay tubes contained 1 fmol of vasopressin tracer purchased from Amersham (Buckinghamshire, UK). After $72 \mathrm{~h}$, bound and free ligand were separated with Ficoll ${ }^{\circ}$-dextran-coated charcoal. The intra- and interassay coefficient of variation were $7.1 \%$ and $8.6 \%$, respectively. Non-specific binding was $<3 \%$ and binding 
of tracer by excess antibody was $90 \%$ with our assay. The detection limit was 0.5 $\mathrm{pmol} / \mathrm{g}$ protein.

\section{Statistics}

The data were subjected to a one factor (age) analysis of variance, followed by the Newman-Keuls test for post hoc multiple comparisons. For data on brain VP concentrations, Pearson's correlation coefficients were calculated and assessed for significance using the Student $t$-test.

\section{RESULTS}

Figure $1 \mathrm{~A}, \mathrm{~B}$ and $\mathrm{C}$ shows concentrations of $\mathrm{VP}$ in the hypothalamoneurohypophyseal system of Wistar rats of different ages. Age-related changes were observed for plasma (Fig. 1A, $P<0.001$ ), the hypothalamus (Fig. $1 \mathrm{~B}, P<0.05$ ) and the posterior lobe of the pituitary (Fig. 1B, $P<0.01$ ). Post hoc multiple
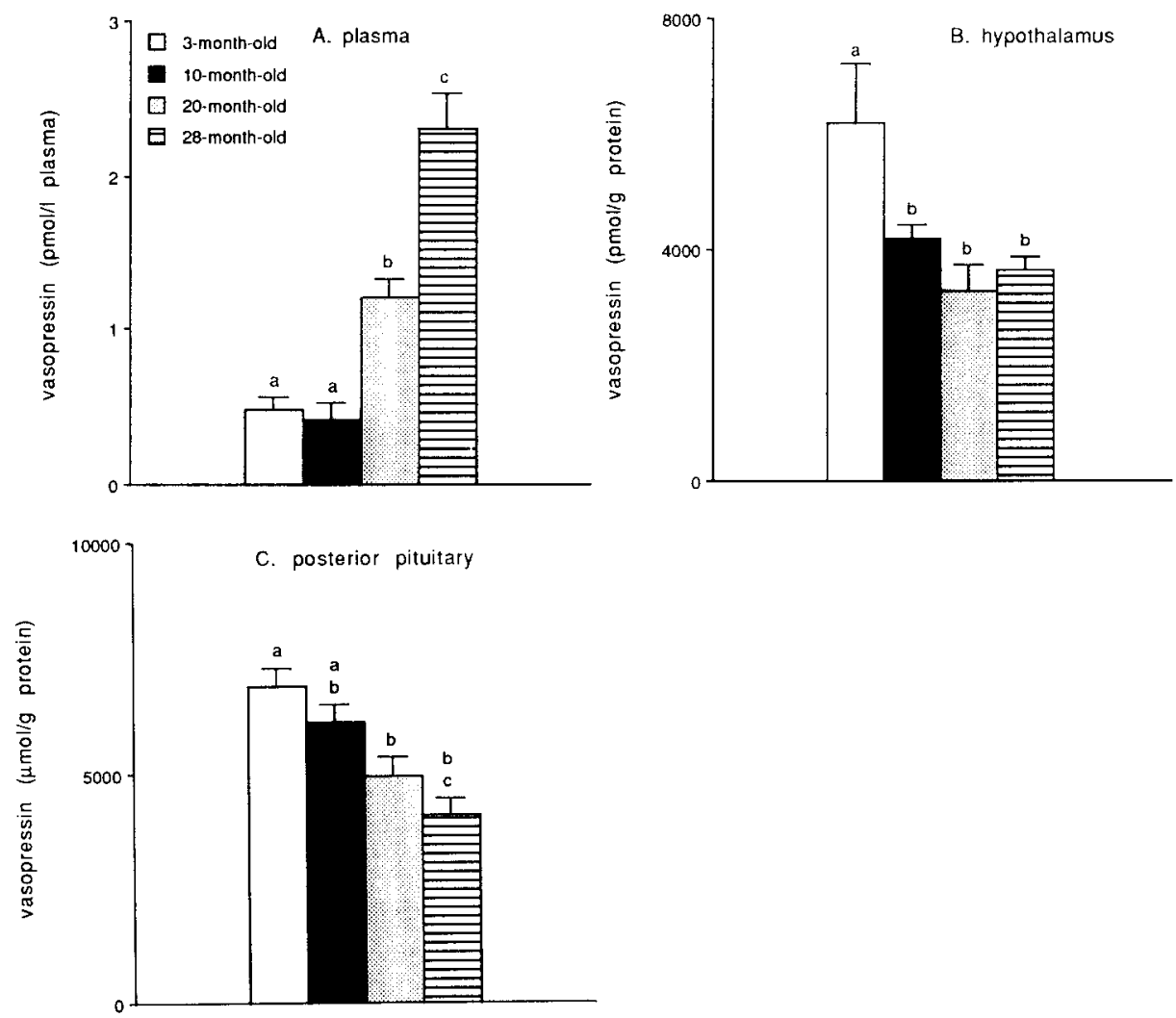

Fig. 1. Concentrations of VP in the hypothalamo-neurohypophyseal system of 3-, 10-, 20- and 28-monthold male Wistar rats. Values significantly different are indicated by different characters. Values not different are indicated the same character. 
comparison revealed that the concentration of VP in the hypothalamus was lower in 20- and 28-month-old rats than in 3- and 10-month-old rats. The level of VP in the posterior pituitary lobe was lower in 20-month-old rats than in 3-month-old rats and lower in 28-month-old than in 10-month-old rats. Plasma VP concentrations were similar in 3- and 10-month-old rats but thereafter increased with age.

Age-related changes in concentrations of VP were also observed in various extrahypothalamic areas (Fig. 2A,B). The VP concentrations showed age-related changes in the midbrain $(P<0.001)$, medulla oblongata $(P<0.001)$ (Fig. 2A), amygdala $(P<0.05)$, pineal gland $(P<0.05)$ and thalamus $(P<0.01)$ (Fig. $2 \mathrm{~B})$. Concentrations of VP in the amygdala and pineal gland were highest in 3-month-old rats. VP concentrations in the medulla oblongata and midbrain decreased with age and those in the thalamus were lower in 20- and 28-month-old rats than in 3- and 10-month-old rats.
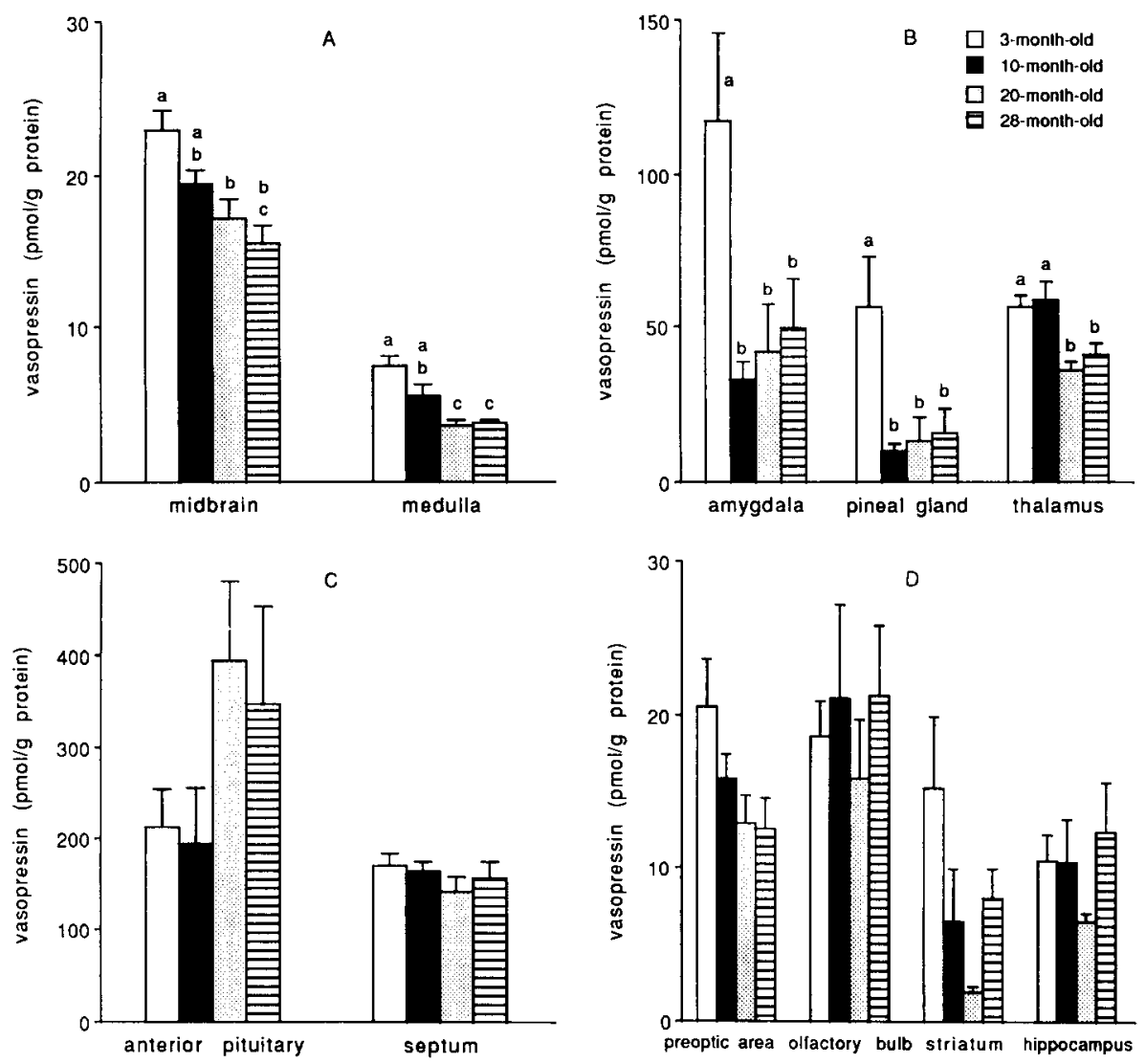

Fig. 2. Concentrations of VP in extrahypothalamic brain regions of 3-, 10-, 20- and 28-month-old male Wistar rats. Values significantly different are indicated by different characters. Values not different are indicated by the same character. 


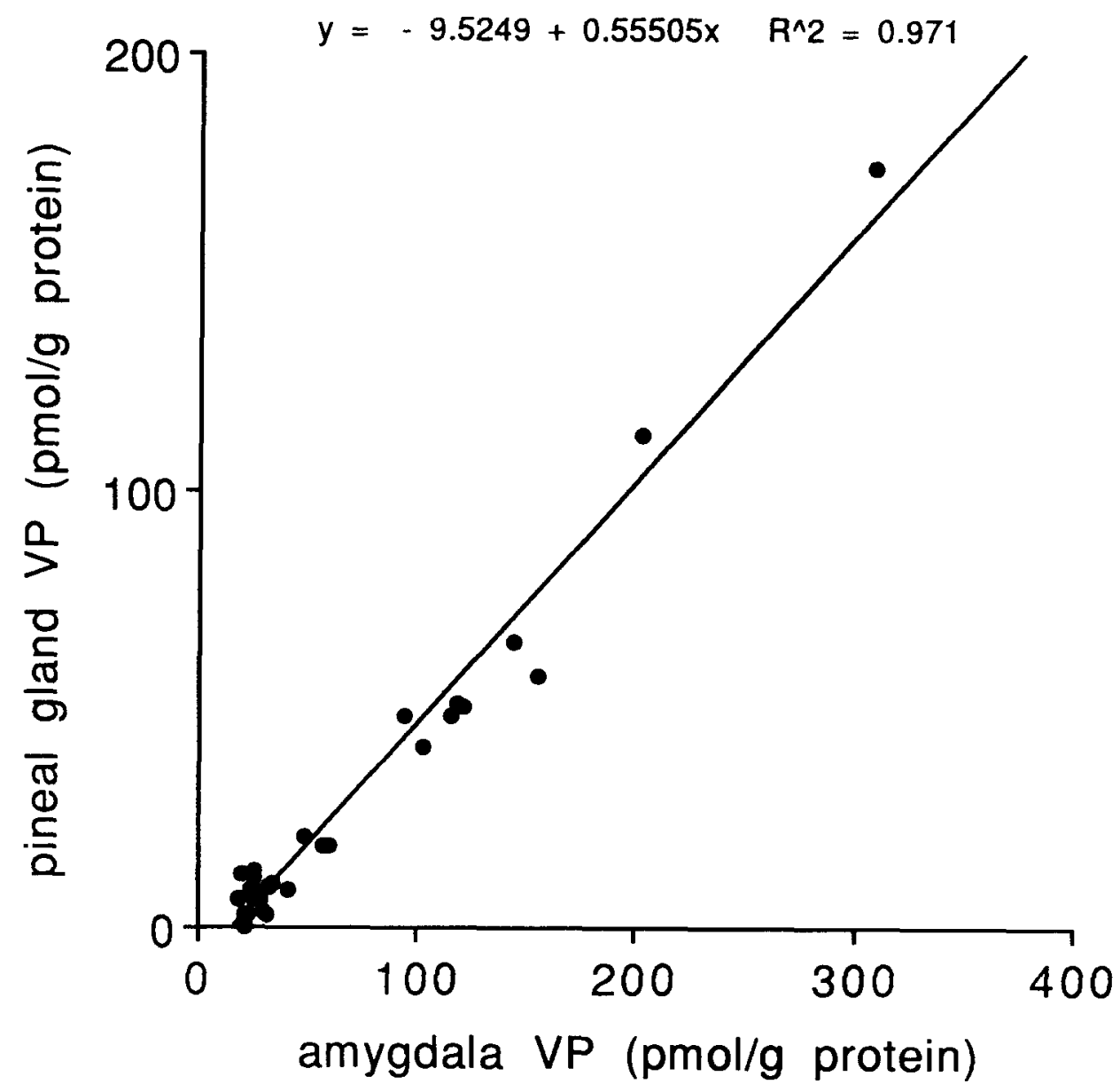

Fig. 3. Relationship between concentrations of VP in the amygdala and pineal gland.

No significant changes in concentrations of VP were observed with age in the anterior pituitary, septum, preoptic area, olfactory bulb, striatum and hippocampus (Fig. 2C,D; $P$ values $>0.05$ ).

To investigate whether the decreases in VP concentrations were related, correlation coefficients were calculated for data on plasma and brain structures. A high correlation was found between the concentrations of VP in the amygdala and pineal gland $\left(r^{2}=0.97, P<0.001\right.$, Fig. 3). Other correlations were not significant.

\section{DISCUSSION}

Not all differences observed between young adult and old rats can be attributed to aging. Young adult rats, for instance, may not have matured completely, which implies that developmental changes contribute to the differences. This is why we 
used four age groups to discriminate between aging and development. Indeed, changes in the concentration of VP were observed between 3 and 10 months of age, in the hypothalamus, amygdala and pineal gland and these are thus probably associated with development. Changes in the pituitary, medulla oblongata, midbrain, thalamus and plasma continued after 10 months of age and can be taken to reflect aging.

The literature on the influence of aging on the hypothalamo-neurohypophyseal system is conflicting. These discrepancies cannot be attributed entirely to strain differences. The present results confirm the finding of Fliers and Swaab [28] that the basal plasma VP concentration increases with age in Wistar rats. These investigators observed increased plasma VP concentrations in 32-month-old Wistar rats [28] as compared to animals younger than 11 months of age. We already observed increased plasma VP concentrations in Wistar rats of 20 months, which can be regarded as middle-aged, but not old. It is important to note that we handled our rats before experimentation and that the animals showed no signs of stress. This was done to control for the possibility, suggested by Silverman et al. [21], that the increased plasma VP concentrations in old animals reflect an increased sensitivity to stress. This is the first time that the influence of age on pituitary and hypothalamic contents in Wistar rats has been determined by radioimmunoassay. The decreased concentrations of VP in the pituitary of aged rats do not imply a reduced neurosecretory activity, since plasma VP concentrations were clearly increased. In fact, the picture observed in aged Wistar rat is not unlike that observed in young animals undergoing osmotic stress [33]. In rats, a decline in VP concentration in the pituitary has been observed after 3 days of water deprivation. Three days' dehydration did not alter VP concentrations in the hypothalamus, which is probably indicative of increased synthesis and transport of the hormone within the hypothalamo-neurohypophyseal system [34]. Our findings thus underscore the notion that the hypothalamoneurohypophyseal system becomes activated with age. It has been suggested that a reduced kidney function activates the neurosecretory cells [35]. However, Miller [19] suggested that the increased VP concentration is the cause of a decreased kidney function. This opinion would seem less likely in view of the fact that in some strains of rats a rise in plasma VP concentration is not observed, whereas kidney function is diminished [36,37]. The discrepancies in the studies on the influence of age on the fluid state may be related to the "use it or loose it" principle advocated by Swaab [38]. In rats, a disturbance in kidney function may be the trigger that activates neurosecretory cells. When kidney function does not decline or declines "too late", activation may no longer be possible. Subtle differences between groups of rats in, for instance, water intake and kidney function may alter the course of alterations in fluid state in rats with age.

VP disappears from a number of brain structures after castration [17], including the septum, hippocampus, amygdala and midbrain. Although the testosterone status decreases with age in several strains of rats $[26,39,40]$, changes in the VP innervation 
dependent on testosterone have not been consistently found [25,26]. Fliers et al. [25] noticed a remarkable similarity between the decreased vasopressinergic fiber density with age and the decreased VP innervation after castration, but Goudsmit et al. [26] only found a diminished staining in the central gray. Goudsmit et al. [26] argued that the intense staining in their study as compared to the study of Fliers et al. [25] may have contributed to this difference. In the present study changes in VP concentrations in some of the structures of which the VP innervation depends on testosterone, were not observed with radioimmunoassay either. In accordance with the previous reports mentioned $[25,26]$ a decline in the VP concentration in the midbrain was found. Therefore, the only consistent decline in VP concentration related to a testicular decline in aged rats, appears to be observed in the midbrain. This is an important finding, since the release of VP in midbrain structures appears to be especially important for improved performance of rats in the passive avoidance test [15]. In this context, it is interesting to note that the impairment in conditioned taste aversion in old rats can be restored by administration of VP [41].

The high correlation between concentrations of VP in the amygdala and pineal gland suggests that the concentration of VP in these structures is regulated by a common factor. This factor cannot be testosterone since the decrease in plasma testosterone concentration is too modest to explain the sharp decrease in VP concentration in the amygdala and pineal gland between 3 and 10 months of age. Another alteration that occurs with maturation in Wistar rats is the loss of $\beta$-adrenergic receptors in the pineal gland during the light period after 3 months of age [42]. Whether this alteration is related to the decrease in the concentration of VP in the pineal gland and how the concentrations in the pineal gland and amygdala are synchronized remains to be demonstrated. Significant correlations between changes in other structures were not observed. This may be related to the fact that at one or both sites compared, VP is not synthesized. The release of VP at vasopressinergic terminals is probably too variable to allow correlations in concentrations to be seen. With respect to the medulla oblongata, VP appears to be involved in central regulation of the cardiovascular reflex [12]. The gradual decline in the concentration of VP in the medulla oblongata may be related to cardiovascular changes and changes in the autonomic nervous system with age (e.g., decreased contractility of the cardiac muscle [43], decreased sensitivity of target organs [44], reduced parasympathetic [45] or increased sympathetic drive [46]). In fact, it has been shown that administration of VP in aged rats reinstates stress-related parasympathetic control of cardiac functioning [47].

In summary, vasopressinergic systems in the brain show different changes with age. The hypothalamo-neurohypophyseal system appears to be activated from middle-age onwards in Wistar rats. Changes observed in the amygdala and pineal gland are better characterized as being related to maturation rather than to aging. Structures of which the VP innervation is testosterone-dependent did not generally show a decline in VP concentrations with age. The present results indicate that it is 
important to use more than two age groups in aging studies in which young and old are compared. In addition, the observation that aging in relation to the vasopressinergic systems is already apparent in middle-age deserves further investigation.

\section{REFERENCES}

1 M.J. Reymond, A. Donda and T. Lemarchand-Béraud, Neuroendocrine aspects of aging: experimental data. Horm. Res., 31 (1989) 32-38.

2 J. Meites, R. Goya and S. Takahashi, Why the neuroendocrine system is important in aging processes. Exp. Biol., 22 (1987) 1-15

3 S.R. Gambert, T.L. Garthwaite, C.H. Pontzer and T.C. Hagen, Age-related changes in central nervous system beta-endorphin and ACTH. Neuroendocrinology, 31 (1980) 252-255.

4 N. Barden, A. Dupont, F. Labrie, Y. Méraud, D. Rouleau, H. Vaudry and J.R. Boissier, Agedependent changes in $\beta$-endorphin content of discrete rat brain nuclei. Brain Res., 208 (1981) 209-212.

5 A. Dupont, P. Savard, Y. Merand, F. Labrie and J.R. Boissier, Age-related changes in central nervous system enkephalins and substance P. Life Sci., 29 (1981) 2317-2322.

6 N. Ogawa, Y. Hirose and M. Nomura, Biochemical and functinal aspects of neuropeptides and their receptors in aged-rat brain. In: H. Yoshida (ed.), Recent Research on Transmitter Receptors, Excerpta Medica, Amsterdam, 1986, pp. 56-71.

7 M.M. Miller, D. Joshi, R.B. Billiar and J.F. Nelson, Loss of LH-RH neurons in the rostral forebrain of old female C57BL/6J mice. Neurobiol. Aging, 11 (1990) 217-221.

8 J.Y. Wei, D. Mendelowitz, N. Anastasi and J.W. Rowe, Influence of age on cardiovascular reflex response in anesthetized rats. Am. J. Physiol., 249 (1985) R31-R38.

9 A.V. Ferguson, L. Bauce and K.E. Cooper, An investigation of the age-related deficits in the fibrile response of the rabbit. Am. J. Physiol., 245 (1983) R379-R385.

10 P.F. Aravich and J.R. Sladek, Jr., Aging of rodent VP systems. In D.M. Gash and G.J. Boer (eds.), Vasopressin. Principles and Properties, Plenum Press, New York, 1987, pp. 579-610.

11 M. Gallagher and A. Pelleymounter, Spatial learning deficits in old rats: a model for memory decline in the aged. Neurobiol. Aging, 9 (1988) 549-556.

12 A.W. Cowley and J.-F. Liard, Cardiovascular actions of vasopressin. In D.M. Gash and G.J. (eds.), Vasopressin. Principles and Properties, Plenum Press, New York 1987, pp. 389-433.

13 N.W. Kasting, Criteria for establishing a physiological role for brain peptides, A case in point: the role of vasopressin in thermoregulation during fever and antipyresis. Brain Res. Rev., 14 (1989) $143-153$.

14 E.B. Verney, The antidiuretic hormone and the factors which determine its release. Proc. R. Soc., B135 (1947) 25-106.

15 P.L. Hoffman, Central nervous system effects of neurohypophyseal peptides. In S. Udenfriend and J. Meienhofer (eds.), Chemistry, Biology and Medicine of Neurohypophyseal Hormones and their Analogs, Academic Press, Orlando, 1987, pp. 239-295.

16 M.V. Sofroniew. Vasopressin, oxytocin and their related neurophysins. In A. Björklund and T. Hökfelt (eds.), Handbook of Chemical Neuroanatomy. Vol. 4: GABA and Neuropeptides in the CNS, Part I, Elsevier, Amsterdam, 1985, pp. 93-165.

17 G.J. de Vries, R.M. Buijs and F.W. van Leeuwen, A.R. Caffé and D.F. Swaab, The vasopressinergic innervation of the brain in normal and castrated rats. J. Comp. Neurol., 233 (1985) 236-254.

18 B. Liu, J.P.H. Burbach, J.D. Femstrom and F.A. Antoni, The hypothalamus is not the origin of vasopressin and oxytocin in the rat pineal gland. Neuroendocrinology, 53 (1991) 523-527.

19 M. Miller, Influence of aging on vasopressin secretion and water regulation. In R.W. Schrier (ed.) Vasopressin, Raven Press, New York, 1985, pp. 165-170.

20 C.D. Sladek, T.H. McNeill TH, C.M. Gregg and M.L. Blair, Vasopressin and renin response to dehydration in aged rats. Neurobiol. Aging, 2 (1981) 293-302. 
21 W.F. Silverman, P.A. Aravich, J.R. Sladek, Jr. and C.D. Sladek, Physiological and biochemical indices of neurohypophyseal function in the aging Fischer rat. Neuroendocrinology, 52 (1990) 181-190.

22 V.K. Zbuzek and W. Wu, Age-related vasopressin changes in rat plasma and the hypothalamohypophyseal system. Exp. Gerontol., 17 (1982) 133-138.

23 V.K. Zbuzek, V. Zbuzek and W. Wu, The effect of aging on vasopressin system in Fischer 344 rats. Exp. Gerontol., 18 (1983) 305-311.

24 D.M. Dorsa and L. Bottemiller, Age-related changes of vasopressin content of microdissected areas of the rat brain. Brain Res., 242 (1982) 151-156.

25 E. Fliers, G.J. de Vries and D.F. Swaab, Changes with aging in the vasopressin and oxytocin innervation of the rat brain. Brain Res., 348 (1985) 1-8.

26 E. Goudsmit, E. Fliers and D.F. Swaab, Testosterone supplementation restores vasopressin innervation in the senescent rat brain. Brain Res., 473 (1988) 306-313.

27 P. Coleman, C. Finch and J. Joseph, The need for multiple time points in aging studies. Neurobiol. Aging, 11 (1990) 1-2.

28 E. Fliers and D.F. Swaab, Activation of vasopressinergic and oxytocinergic neurons during aging in the Wistar rat. Peptides, 4 (1983) 165-170.

29 J. Kirkland, M. Lye, C. Goddard, E. Vargas and I. Davies, Plasma arginine vasopressin in dehydrated elderly patients. Clin. Endocrinol., 20 (1984) 451-456.

30 I. Os, S.E. Kjelsen, I. Aakesson, J. Skjø I. Eide, I. Hjermann and P. Leren, Evidence of age-related variation in plasma vasopressin of normotensive men. Scand. J. Clin. Invest., 45 (1985) 263-268.

31 W.H. Gispen, P. Schotman and E.R. de Kloet, Brain RNA and hypophysectomy; a topographical study. Neuroendocrinology, 9 (1972) 285-296.

32 J.A. ten Haaf, D. Terwel, H.J.M. van de Heijning and Tj.B. van Wimersma Greidanus, Radioimmunoassay: a goal or a tool? J. Control. Rel, (in press).

33 A. Negro-Vilar and W.K. Samson, Dehydration-induced changes in immunoreactive vasopressin levels in specific hypothalamic structures. Brain Res., 169 (1979) 585-589.

34 R.L. Zerbe and M. Palkovits, Changes in the vasopressin content of discrete brain regions in response to stimuli for vasopressin secretion. Neuroendocrinology, 38 (1984) 285-289.

35 R. Ravid, E. Fliers, D.F. Swaab and C. Zurcher, Changes in vasopressin and testosterone in the senescent Brown-Norway (BN/BiRij) rat. Gerontology, 33 (1987) 87-98.

36 H.H. Bengele, R.S. Mathias, J.H. Perkins and E.A. Alexander, Urinary concentration defect in the aged rat. Am. J. Physiol., 240 (1981) F147-150.

37 E. Goudsmit, E. Fliers and D.F. Swaab, Vasopressin and oxytocin excretion in the Brown-Norway rat in relation to ageing, water metabolism and testosterone. Mech. Ageing Dev., 44 (1988) 241-252.

38 D.F. Swaab, Brain aging and Alzheimer's disease, "wear and tear" versus "use it or lose it". Neurobiol. Aging, 12 (1989) 317-324.

39 L.W. Kaler and W.B. Neaves, The androgen status of aging male rats. Endocrinology, 108 (1981) 712-719.

40 K.C. Chambers and C.H. Phoenix, Testosterone and the decline in sexual behavior in aging male rats. Behav. Neural. Biol., 40 (1984) 87-97.

41 R.C. Cooper, M.C. McNamara and W.G. Thompson, Vasopressin and conditioned flavor aversion in aged rats. Neurobiol. Aging, 1 (1980) 53-57.

42 E.M. Dax and D. Sugden, Age-associated changes in pineal adrenergic receptors and melatonin synthesizing enzymes in the Wistar rat. J. Neurochem., 50 (1988) 468-472.

43 J.M. Capasso, M. Ashwani, R.M. Remily, J. Scheuer and E.H. Sonnenblick, Effects of age on mechanical and electrical performance of rat myocardium. J. Am. Physiol., 245 (1983) H72-H81.

44 I.B. Davies and P.S. Sever, Adrenoceptor function. In R. Bannister (ed.) A Textbook of Clinical Disorders of the Autonomic Nervous System, Oxford University Press, Oxford, 1988, pp. 348-366.

45 B. Buwalda, C. Nyakas, J.H. Strubbe, M. Hoes and B. Bohus, Age-related reduction in parasympathetic responses in the rat. In C.F.A. van Bezooijen, R. Ravid and A.A.J. Verhofstad (eds.), From Gene to Man. Gerontological Research in The Netherlands, Stichting Gerontologie en Geriatrie, Rijswijk, 1990, pp. 90-94.

46 T.S. Tanabe and R.D. Bunag, Age-related central and baroreceptor impairment in female Sprague-Dawley rats. Am. J. Physiol, 256 (1989) H1399-1406.

47 C. Nyakas, A.J.A. Prins and B. Bohus, Cardiac responses and behavioral reactivity to emotional stress in aged rats. Proc. 27th Dutch Fed. Meeting (1986) 295 pp. 